\title{
Small Water Landscape Water Treatment Process Optimization Research
}

\author{
Ping $\mathrm{Hu}^{1, \text { a }}$, Qingping Yang *2,b , Hongxia Huang ${ }^{\star 3, c}$ \\ 1,2,3 College of Life Science and Technology, Hubei Engineering University, Hubei, Xiaogan, 432000, \\ China \\ ahuping 2001@163.com, byangqingping9@126.com, chongxiah2009@126.com
}

Keywords: Small surface; Landscape water body; Treatment process; Comparison and analysis Abstract. The small near the surface of the landscape water body because of the influence of water quality deterioration and gradually people's normal life, need to take certain measures of water conservation and water treatment was carried out on the water quality protection. Traditional method from the surface of the water landscape water treatment, such as physical method, chemical method, biological prevention and control were analyzed, and all kinds of small water landscape water treatment process, based on the characteristics of various methods, analyzed and analyzes its advantages and disadvantages, puts forward the future of small water landscape water treatment process optimization of the main research direction, and provide reference for the practice of this kind of water treatment.

City park lake is enclosed water more, generally has the waters area is small, easy to pollution, water environmental capacity of small, low water self-purification ability, is vulnerable to pollution, and presents the eutrophic state, embodied in the water green, even hydration phenomena occur, low transparency, fish died, water smells etc. Phenomenon ${ }^{[1]}$. Eutrophic water body for visitors to cause adverse effect, leisure, entertainment and other activities, must carry out effective governance.

\section{Small water landscape water traditional processing methods}

Small water landscape water refers to the smaller city parks and small lakes or pools in the residence community. City small water landscape water is the main pollution sources of non-point source pollution, such as natural rainfall and surface runoff nutrient pollution, atmospheric dust, underground water, long-term accumulation of lake bottom mud and silt release of harmful substances, etc. Most small landscape water is recirculated water due to the lack of the water, dissolved oxygen (do) is too low, poor environment, water plants and animals gradually lose water self-purification ability, eventually lead to eutrophication and algal blooms, water quality deterioration, loss of ornamental value ${ }^{[1]}$. Small water landscape water traditional processing method mainly includes: physical method, chemical method and biological method.

\section{Physical methods}

(1) Filtering method. Filtering method for small water landscape water treatment effect is best, especially the removal of turbidity. Filtering method for algae removal rate is very high. Cylinder of the traditional sand filtration in less than $500 \mathrm{t}$ of the successful application of landscape water treatment, but for more than $500 \mathrm{t}$ medium lake water effect is bad [2], because traditional sand generally adopts the single or double cylinder quartz sand, large amount of algae, easy blocking sand cylinder plug.

(2)The water cycle. It is using the pump will not flow pump water to the main loop over the waters of the river basin, with the center the main loop basin is built into a number system. Water in the process of flow, there will be a lapping, rapids, whirlpool, waterfalls, mixed gas water, improve dissolved oxygen content in water, thus ensuring water quality fresh. But the downside is need built water treatment station, power consumption, has a blind Angle, effect. 
(3) The aeration method. By air flotation machine, filtration equipment, access to a large number of tiny air bubbles to the water, stick on the water particles, and the buoyancy to rise to the surface of the water, was finally blown away material of a kind of method to deal with the water algae ${ }^{[3]}$. Aeration method need air flotation equipment, power consumption is larger, but the water landscape water using "drop aeration method" effect is good, drop aeration method is to use the potential energy, less power consumption, is ideal method. Large water landscape water gas floating aeration method can be used and blower aeration method.

The existence of dissolved oxygen in water, can make the metabolism of aerobic microorganisms by itself to the degradation of organic pollutants in the water into simple inorganic, self-purification of water body. The consumption of dissolved oxygen in water, causing water anoxic and anaerobic microbes, causing water black stunk. Therefore, should maintain a certain level of dissolved oxygen in water body. In order to increase the dissolved oxygen (DO) in the water, and further strengthen the liquidity pool, to pool submerged aeration measures taken to prevent the propulsion system formed in the process of pushing flow blind Angle.

(4) The electromagnetic processing. Using electromagnetic wave or ultrasonic method is a method of sterilizing alga, accused of algae. Can computer control, automatic timing open, convenient, but requires independent main equipment platform, pulse pressure ionized water processor, magnetic processor, such as equipment, large investment.

\section{Chemical methods}

(1) Adding coagulant, flocculation agent. Through to the chemical material such as landscape water with alum and polyacrylamide and the suspended solids in the water flocculation body formation, and then through filtration equipment filtering or through an air floated equipment of foam machine is removed from the water. Can be used as an auxiliary method of water treatment equipment efficiency, but increase the cost of water treatment and cause of secondary pollution to the water body.

(2) Add disinfectant. To add a small amount of chlorine preparation, landscape water can inhibit the growth of algae spores in water for a long time, and can control the growth of the mosquito larvae wiggler. Chlorine preparation is low in price, but to control volume, a small amount of additive can have very good effect, so widely used in landscape water in the engineering practice.

\section{The prevention and control}

(1) Aquatic animals and plants. Some floating plants such as duckweed, water hyacinth has extremely strong vitality and reproduction ability, can quickly absorb the N, P and other nutrients in the water, and then by the method of harvest, remove nutrients from the water. Submerged plant such as aquatic plants through photosynthesis can increase the dissolved oxygen in the water, a water plants can help to reduce the bottom silt ${ }^{[4]}$. Aquatic animals like silver carp with algae as food. Take silver carp growth per $1 \mathrm{~kg}$, can eat 100--100 kg cyanobacteria, through the fish catch, remove nutrients in the water, so as to reduce lakes pollution load, the purpose of improving water quality. In Wuhan east lake eutrophication of water bodies such as $50 \mathrm{~g} / \mathrm{m}^{2}$ of silver carps or oxtail, make the micro capsule algal bloom has been effectively suppressed.

(2) The microbial method. Under the condition of dissolved oxygen in water is enough, aerobic microorganisms dominant, aerobic microbial organic matter can be fully decomposed. Dissolved oxygen in the water shortage situation, the anaerobic microorganisms dominant, anaerobic microorganisms will be incomplete decomposition of organic matter, and release the smelly gas such as hydrogen sulfide, affect the quality of landscape ${ }^{[5]}$. Microbial control method of water treatment efficiency is high, but the investment is big, covers an area of large, high cost. 


\section{Small water landscape water treatment process optimization}

Traditional processing method of landscape water each have advantages and disadvantages, single use some methods for small water landscape water treatment effect is not ideal, must be comprehensive, optimization of process. The following design scheme, confirmed in practice, the effect is better.

The area of the urban residential area landscape water generally small, water capacity under 500 $t$, most of the sight of the water in the water supply design use tap water, more water landscape of the high cost of operation, and once the limited use of tap water, landscape water body becomes madrassa reflected. In order to reduce the amount of water, saving cost and can be used "chemical method + filtration method" and "filtration + drop aeration method".

(1) Chemical method + filtering method. For some of the smaller water filtration purification method combined with drug treatment can be used, such as the Hubei Engineering University Post Garden District area waterscape, aquatic ecosystem is fragile, after adding the purification measures of bleaching powder and not chemical dosage compared to change water number was reduced to 4 times a year, to save the running cost. Commonly used water treatment agents are mainly copper sulfate, bleaching powder, etc., but need to pay attention to control the good additive dosage, avoid the side effects.

(2) Filtering method + drop aeration method. Such as good effect in the process, using a district in Wuhan. The characteristics of the landscape water processing method is simple, low cost, good effect, suitable for small area of the landscape water body purification treatment, but takes up the area is larger, need recoil water discharge.

City parks most lakes in the use of nature water, water quality protection measures should be considered in design at the same time create good water ecological system and to enhance water self-purification ability. Gas floatation process can be used and the method of aquatic animals and plants.

(3) The gas floatation process. The process includes: gas floating aeration method + add coagulant flocculants method + flotation foam. The characteristics of the process: water treatment effect is good, small water turbidity, but covers an area of big, operation cost is higher, need the embalming process.

(4) Of aquatic animals and plants. Use of the advantages of aquatic animals and plants governance is no investment in equipment, less investment, long-term effect. The disadvantage is that covers an area of big, effective slow, need professional maintenance company, on the turbidity of water did not improve, must cooperate with other process. Generally is a closed water for landscape water, and water ecosystem is relatively weak, established by the artificial ecological system is easy to break, into a vicious cycle. In addition, although can control algae floating plants such as water gourd, but due to the ability to reproduce is too strong, control is not good, also can produce excess growth ${ }^{[6]}$. Maintenance management method of aquatic plants and animals need professional company. Aquatic animals and plants management method is suitable for large lakes, the water such as lakes was tested in Xiaogan Huaiyin Park, effect is good, but need to cooperate with other methods to solve the problem of turbidity.

\section{Three kinds of landscape water treatment technology}

Comprehensive investment and benefit, can be seen from table 3.1, suitable for small water landscape water treatment technology are now a "drop aeration method + filtration method," followed by "chemical method + filtration method", good condition city parks, large surface of the lake can choose "air flotation process", where there are professional maintenance, "method" of aquatic plants 
and animals can be used, but the method must be used together with other methods, aquatic plants and animals otherwise cannot achieve the ideal effect, high turbidity.

Table 3.1 kinds of landscape water treatment technology is compared

\begin{tabular}{|c|c|c|c|c|c|c|}
\hline $\begin{array}{l}\text { Treatment } \\
\text { processes }\end{array}$ & $\begin{array}{l}\text { Initial } \\
\text { investment }\end{array}$ & $\begin{array}{l}\text { Total } \\
\text { area }\end{array}$ & $\begin{array}{l}\text { Operational } \\
\text { cost }\end{array}$ & $\begin{array}{l}\text { Maintenance } \\
\text { measures }\end{array}$ & $\begin{array}{l}\text { Treatment } \\
\text { effect(turbidity) }\end{array}$ & Time/year \\
\hline $\begin{array}{l}\text { Chemical } \\
\text { method } \\
+ \text { filtration }\end{array}$ & small & small & low & None & $<10$ & 1 \\
\hline $\begin{array}{l}\text { Drop } \\
\text { aeration } \\
\text { method } \\
+ \text { filtering } \\
\text { method }\end{array}$ & big & middle & low & none & $<5$ & 30 \\
\hline $\begin{array}{l}\text { Air flotation } \\
\text { method }\end{array}$ & middle & big & high & embalmed & $<10$ & 5 \\
\hline $\begin{array}{l}\text { Method of } \\
\text { aquatic } \\
\text { organisms }\end{array}$ & small & big & low & $\begin{array}{c}\text { profeesshional } \\
\text { maintenance }\end{array}$ & high & 1 \\
\hline
\end{tabular}

To sum up, the choice of landscape water treatment process should be set according to the actual situation, to comprehensively consider the early investment and maintenance cost, need to achieve the effect, the condition of raw water, filling water source, small water landscape water treatment processes can be considered with two or more methods, in order to achieve maximum benefit.

\section{Acknowledgements}

This work was financially supported by the Hubei Province Science and Technology Research Plan Guidance Project (B2016177) and Hubei Engineering University Science Research Project (Z2014007).

\section{References}

[1] H. Cheng, X.Y. Chen, J. Liu etc, Analysis of urban landscape water pollution and its control technology research progress .J. Journal of Anhui agricultural science, 38 (6): 3102-3104.(2010)

[2] Y. Qing. Chongqing Three Gorges square landscape water treatment research .D. Chongqing: Chongqing University (2007)

[3] Z. W. Zhao, W. M. Li, H. Gao etc, Such as air flotation process to strengthen the pilot test study to remove algae in .J. Journal of Shenyang University, 12 (2) : 62-65(2007)

[4] G. Yang, L. Tu, R. Qin etc. Residential area water environment protection of water use in landscape application.J. Journal of Yunnan environmental science, 23 (1) : 25-26(2004)

[5] Y. Q. Guo, Urban landscape water body pollution control and remediation technology .J. Journal of environmental science and technology, 6:30-34(2005)

[6] X. M. Yin, J. P. Xu, Urban landscape water pollution present situation and the countermeasures study .J. Journal of Anhui institute of engineering technology, 4 (23) : 28-31(2008) 